\title{
Carcinoma Espinocelular cutâneo bem diferenciado: apresentação atípica
}

Vinícius Figueiredo CARNEIRO ${ }^{1}$

Carolina Lamac FIGUEIREDO ${ }^{2}$

Paula Grisolia Oliveira Netto SOARES ${ }^{3}$

Erlon de Ávila CARVALHO ${ }^{3}$

Karina Noman FERREIRA ${ }^{5}$

Walter Ferraz Flávio JÚNIOR ${ }^{6}$

Reni Cecília Lopes MOREIRA ${ }^{7}$

Seiji MIYATA ${ }^{8}$

Cássio Andrade CINTRA ${ }^{9}$

${ }^{1-2}$ Médicos residentes de cirurgia geral R2 no Instituto Mário Penna

${ }^{3}$ Médica residente de clínica médica R2 no Hospital João XXIII - FHEMIG

${ }^{4}$ Médico residente de cancerologia cirúrgica R5 no Instituto Mário Penna

${ }^{5}$ Acadêmica do $12^{\circ}$ período da Faculdade de Medicina da Universidade Federal de Minas Gerais

${ }^{6}$ Médico residente de cirurgia geral R1 no Instituto Mário Penna

${ }^{7-9}$ Preceptores da Residência de Cirurgia Geral e Cancerologia Cirúrgica do Instituto Mário Penna - Especialistas em Cancerologia Cirúrgica pela SBCANCER

Email: vinafcarneiro@gmail.com (Carneiro, VF), carolina.lamac@gmail.com (FIGUEIREDO, CL), paula_gri@yahoo.com.br (SOARES, PGON), erlon_avila@hotmail.com (CARVALHO, EA), karinanoman@yahoo.com.br (FERREIRA, KN), walter_ferraz@yahoo.com.br (JUNIOR, WFF), renicecilia@hotmail.com (MOREIRA, RCL), seijisilvana@terra.com.br (MIYATA, S), cassioacintra@ig.com.br (CINTRA,CA)

Recebido em: 30/10/2012 - Aprovado em: 28/12/2012 - Disponibilizado em: 30/12/2012

\section{RESUMO:}

O câncer de pele não-melanoma é a neoplasia maligna mais comum no Brasil. Seu subtipo menos frequente, o carcinoma espinocelular (CEC), pode ser agressivo, mas, na maioria das vezes, é completamente curado por medidas terapêuticas locais. Relatamos o caso de uma mulher de 75 anos que apresentava lesão de 2,5 cm em dorso da mão esquerda diagnosticada como CEC bem diferenciado. Foi submetida à ressecção da lesão com margem cirúrgica de 1,5 $\mathrm{cm}$. Após 75 dias da cirurgia, paciente retornou com linfadenomegalia axilar esquerda. Foi realizada biópsia, que conclui tratar-se de CEC bem diferenciado metastático. O tratamento proposto foi linfadenectomia axilar com radioterapia adjuvante. Paciente evoluiu com recidiva axilar ulcerada e dor intensa, sendo realizada ressecção ampliada da lesão. Foi proposto à paciente desarticulação interescapulotorácica e a paciente concordou com a realização do procedimento. Atualmente, encontra-se em controle ambulatorial, sem sinais de recidiva ou metástases à distância. O caso clínico mostra uma evolução atípica de um CEC bem diferenciado, com lesão primária em dorso da mão esquerda e metástase linfonodal axilar precoce, com comprometimento da qualidade de vida. Optamos pela desarticulação interescapulotorácica devido à presença de um tumor localmente avançado, a não funcionalidade do membro, a possibilidade de melhor higienização local e a ausência de metástases em outros sítios.

Palavras-chave: Câncer de pele. Carcinoma Espinocelular. Metástase. Recidiva. Desarticulação interescapulotorácica.

\section{Well-differentiated skin Squamous Cell Carcinoma: an atypical presentation}

\begin{abstract}
:
Nonmelanoma skin câncer is the most common malignant tumor in Brazil. Its less common subtype, squamous cell carcinoma (SCC), can be aggressive, but it's usually completely healed with only local tharepeutic measures. The case reported is about a 75 year-old woman who had a $2,5 \mathrm{~cm}$ lesion on the back of the left hand diagnosed as welldifferentiated SCC. She was submitted to a resection of the tumor with surgical margins of $1,5 \mathrm{~cm}$. After 75 days of
\end{abstract}


surgery, the patient returned with enlarged left axillary lymph node. Biopsy was done, which concluded that it was metastatic well-differentiated SCC. The treatment proposed was axillary lymphadenectomy associated with adjuvant radiation therapy. The patient presented axillary tumor recurrence and severe local pain, being submitted to extended local resection. It was proposed to the patient the interscapulothoracic disarticulation surgery and the patient agreed to the procedure. Currently, the patient is in outpatient control, with no signs of recurrence or distant metastasis. This case shows an atypical presentation of well-differentiated SCC with the primary tumor on the back of the left hand and an axillary lymph node metastasis, with compromised quality of life. The interescapulothoracic disarticulation surgery was the treatment proposed due to the presence of a tumor locally advanced, nonfunctionality of the member, the possibility of better local hygiene and absence of metastasis at other sites.

Key-words: Skin cancer. Squamous cell carcinoma. Metastasis. Recurrence. Interescapulothoracic disarticulation.

\section{INTRODUÇÃO}

Segundo dados do Instituto Nacional do Câncer (INCA), o câncer de pele nãomelanoma (CPNM) é tipo mais comum de neoplasia maligna no Brasil. Em 2012, estimam-se 62.680 novos casos de CPNM entre homens e 71.490 em mulheres, o que corresponde a um risco estimado de 65 novos casos a cada 100 mil homens e 71 para cada 100 mil mulheres. ${ }^{10}$ A despeito de seu impacto para saúde pública e das altas taxas de incidência, o câncer da pele não-melanoma permanece subnotificado pela maioria dos registros de câncer no mundo. No Brasil, figura como o tumor mais incidente em ambos os sexos e é bastante provável que exista um sub-registro devido ao subdiagnóstico. ${ }^{10}$ Aproximadamente $80 \%$ dos CPNM são derivados das células nãoqueratinizadas que originam a camada basal da epiderme - carcinoma basocelular (CBC), enquanto cerca de $20 \%$ surgem da proliferação atípica de queratinócitos suprabasais - carcinoma espinocelular ou escamocelular (CEC). ${ }^{14}$ Ao contrário do $\mathrm{CBC}$, o CEC é geralmente mais agressivo e apresenta maior potencialidade de gerar metástases a distância. ${ }^{2,} 14$ Apesar disso, a imensa maioria dos CEC são somente agressivos localmente e curados, por completo, apenas com medidas terapêuticas regionais. ${ }^{14,15}$

O presente estudo relata a necessidade de intervenção cirúrgica agressiva, desarticulação interescapulotorácica, no tratamento de paciente com CEC cutâneo bem diferenciado em estádio avançado.

\section{RELATO DE CASO}

Trata-se de paciente do sexo feminino, 75 anos, proveniente de Lagoa da Prata MG, encaminhada ao serviço de Cirurgia Oncológica do Hospital Luxemburgo devido a lesão elevada, vegetante, ulcerada, com 2,5 cm de diâmetro, em dorso da mão esquerda, com cerca de 06 meses de evolução. Biópsia incisional evidenciou carcinoma espinocelular (CEC) bem diferenciado. Submetida à ressecção ampliada de lesão em dorso da mão esquerda, com margens cirúrgicas livres, porém exíguas em profundidade. (Figura 1). 
Figura 1 - AP de lesão ressecada em dorso da mâo esquerda: CEC bem diferenciado, com margens cirúrgicas livres, porém exíguas em profundidade

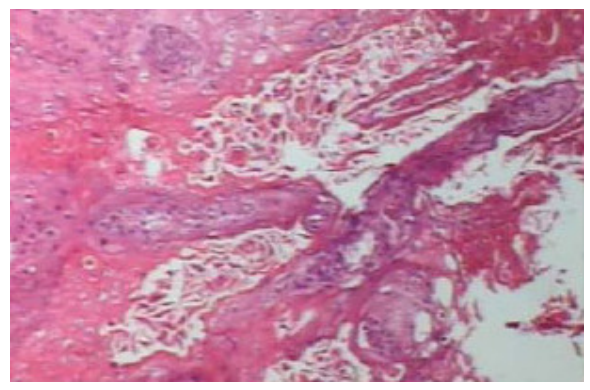

Fonte: $\operatorname{Reg} 657613$

Após 2 meses da cirurgia, paciente apresentou surgimento de nódulo em axila esquerda, cuja biópsia revelou CEC bem diferenciado. Realizado linfadenectomia axilar esquerda, com peça cirúrgica evidenciando presença de 9 linfonodos confluentes e partes moles adjacentes difusamente infiltrados por CEC. Proposto à paciente realização de radioterapia (RT) adjuvante.

Após o término da RT, paciente evoluiu com quadro de recidiva axilar com ulceração local e dor intensa. Paciente foi submetida à nova ressecção ampliada da lesão, sendo observada invasão do feixe vásculo-nervoso axilar.

Após discussão do caso entre os membros da equipe, foi proposto à paciente desarticulação interescapulotorácica. Neste momento, paciente apresentava dor local intensa refratária, perda da sensibilidade e da movimentação de todo o membro superior esquerdo, lesão ulcerada em axila esquerda e aparecimento progressivo de diversos nódulos em parede torácica anterior. (Figura 2)

Figura 2 - Foto pré-operatória de lesão em axila esquerda recidivada ulcerada e implantes em mama esquerda

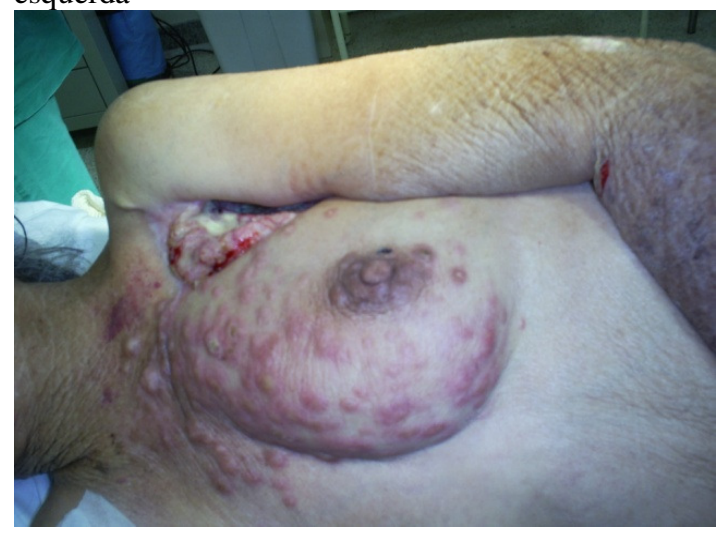

Fonte: Reg 657613

Paciente foi submetida a desarticulação interescapulotorácica esquerda e mastectomia radical esquerda, com rotação de retalhos com aproximação das bordas para fechamento por segunda intenção. (Figuras 3 e 4)

Figura 3 - Foto cirúrgica com aspecto final operatório após amputação interescapulotorácica esquerda com mastectomia radical esquerda; deixada parte da incisão para fechamento por segunda intenção.

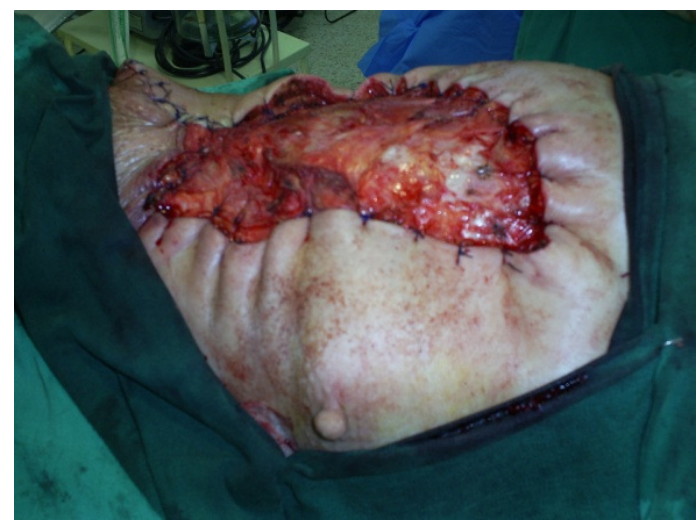

Fonte: Reg 657613 
Figura 4 - Peça cirúrgica (amputação interescapulotorácica esquerda com mastectomia radical esquerda)

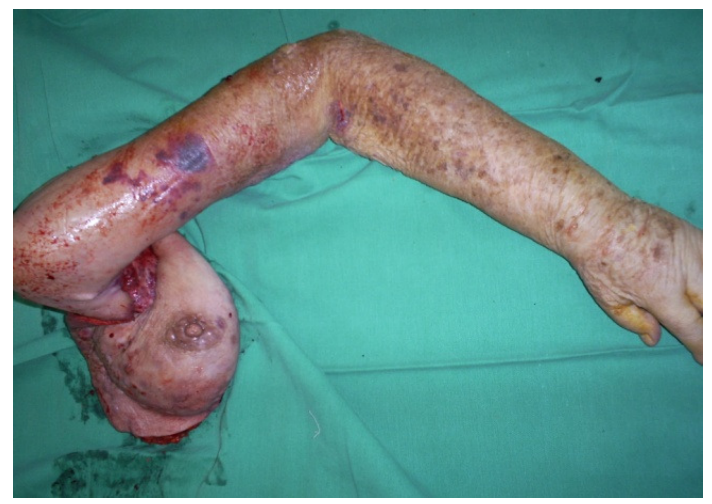

Fonte: Reg 657613

Paciente teve boa evolução pósoperatória e recebeu alta hospitalar no $5^{\circ}$ dia pós-operatório (DPO). O resultado anátomopatológico (AP) concluiu tratar-se de CCE bem diferenciado, invasor, com margens cirúrgicas livres nos planos examinados. (Figura 5)

Figura 5 - AP de peça cirúrgica: CEC bem diferenciado, invasor, com margens cirúrgicas livres nos planos examinados

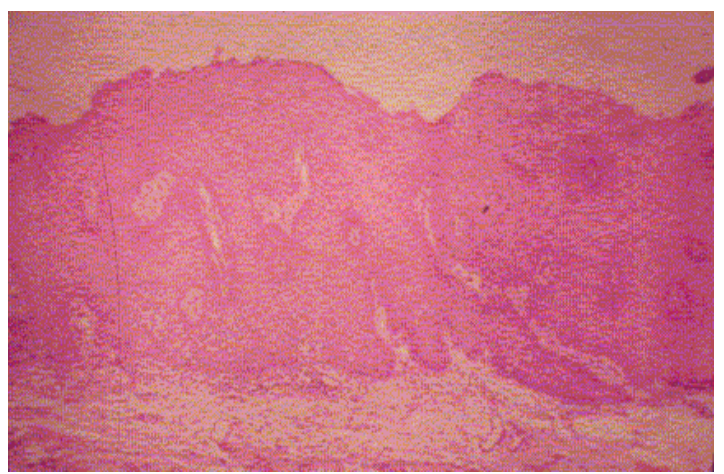

Fonte: Reg 657613

A paciente encontra-se em controle ambulatorial há 2 anos e sem sinais de recidiva local, sem evidências de metástases a distância e sem queixas álgicas.

\section{DISCUSSÃO}

O CEC cutâneo apresenta incidência progressivamente aumentada a partir dos 50 anos de idade, sendo mais comum em homens de pele clara. ${ }^{5,8,15} \mathrm{O}$ principal fator de risco para seu surgimento é a fotoexposição (radiação ultravioleta), causadora de mutações em genes supressores de tumor (p53). ${ }^{2}$ Assim, a maioria dos CEC cutâneos (de 70 a 80\%) ocorrem na região da cabeça e pescoço, áreas corporais prioritariamente expostas ao sol. $^{8}$ Outros fatores de risco para surgimento do CEC cutâneo são exposição a radiação ionizante, xeroderma pigmentoso, HPV, exposição a arsênico ou hidrocarbonetos aromáticos, imunossupressão, transplantados, portadores de linfoma ou leucemia, injúrias crônicas de pele, presença de lesões precursoras, entre outros. ${ }^{2,14,15}$ As lesões comumente apresentam-se como nódulos ou placas eritematosas, hiperceratóticas, com tendência para ulcerar e sangrar facilmente, ou mesmo como feridas de crescimento progressivo que não cicatrizam. ${ }^{14,15}$

Quanto ao grau de malignidade, o CEC situa-se entre o CBC e o melanoma, isto é, não possui nem a agressividade dos melanomas nem o caráter lento e crônico dos CBC. Apesar do CEC cutâneo ser uma neoplasia maligna de pele com pouca possibilidade de metástase, em raros casos pode apresentar uma evolução agressiva - os dados nas mais diversas fontes da literatura 
que afirmam que a incidência de metástases pode ocorrer de 0,1 a $9,9 \%$ dos casos. ${ }^{8}$ Geralmente surgem cerca de 1 a 2 anos após o diagnóstico da lesão primária, ${ }^{8}$ embora casos de apresentações tardias também possam acontecer. $^{3}$ As metástases são mais frequentes no caso de lesões grandes (maiores de $2 \mathrm{~cm}$ ), invasoras de tecidos profundos ou nervos, recorrentes, em localidades específicas do corpo (como lábio, orelha e sobre cicatrizes), pouco diferenciadas, e em pacientes imunossuprimidos. ${ }^{7,8,14}$,

O quadro clínico apresentado pela paciente mostra uma evolução atípica de um CEC bem diferenciado, com lesão primária em dorso da mão esquerda e metástase linfonodal axilar precoce, com comprometimento da qualidade de vida. Um adequado estadiamento da doença é fundamental para o seu correto manejo clínico e cirúrgico.

Metástases de CEC cutâneos para linfonodos axilares são relativamente incomuns, tendo um estudo alemão documentado esta situação em cerca de 3,9\% dos casos de CEC cutâneos originados em tronco e extremidade. ${ }^{7,9}$ Frequentemente os pacientes vem à consulta ambulatorial com queixa de massa indolor de crescimento progressivo em região axilar, sendo que a história de um CEC cutâneo tratado previamente no membro superior ipsilateral nem sempre é passada de forma clara no atendimento. $^{7}$

O adequado manejo dos CEC cutâneos com metástase linfonodal (principalmente daqueles oriundos de lesões primárias em áreas menos expostas ao sol, como as extremidades e o tronco), ainda não é bem documentado e permanece repleto de controvérsias. $^{7}$

Veness et al publicaram, em 2005, um estudo com intuito de comparar o tratamento cirúrgico isolado em relação à cirurgia associada a RT adjuvante em casos de CCE cutâneo metastático - foi evidenciado que o tratamento combinado (cirurgia $+\mathrm{RT}$ adjuvante) gerou taxa de recorrência menor e importante aumento do tempo de sobrevida (tempo livre de doença). ${ }^{12}$

O principal objetivo da RT adjuvante é erradicar qualquer resíduo de doença microscópica e aperfeiçoar o controle locorregional da afecção. A prevenção da recorrência pós-operatória é de grande importância prognóstica, uma vez que pacientes que desenvolvem recidiva linfonodal são usualmente incuráveis, e frequentemente experimentam grande morbidade, com forte dor local, sangramento, entre outros. ${ }^{7}$

Entretanto, a decisão quanto à realização de RT adjuvante ainda permanece controversa. Diretrizes australianas 
consideram significativa extensão extranodal, 4 ou mais linfonodos positivos e margens cirúrgicas comprometidas como as principais indicações para a realização de RT adjuvante. $^{7}$

Quanto ao tratamento com quimioterapia (QT) para o caso de CEC cutâneo metastático, os dados na literatura também são controversos. Entretanto, pode-se dizer que seu uso habitual permanece limitado, uma vez que os atuais estudos demonstram baixas taxas de sucesso com os regimes vigentes. ${ }^{8}$

No caso clínico apresentado, optamos pela desarticulação interescapulotorácica (Cirurgia de Berger) devido à presença de um tumor localmente avançado, a não funcionalidade do membro, a possibilidade de melhor higienização local e a ausência de metástases em outros sítios. A desarticulação interescapulotorácica compreende a ressecção de todo o membro superior e a cintura escapular, incluindo a escápula e uma porção da clavícula. As maiores indicações para este procedimento ablativo são grandes tumores intimamente ligados aos nervos principais ou ao suprimento vascular do membro superior, com importante prejuízo funcional. As principais contraindicações para sua realização são as metástases à distância e os grandes envolvimentos da parede torácica. ${ }^{4,11 \text {, }}$ 13.
A desarticulação interescapulotorácica foi inicialmente descrita para o tratamento de injúrias traumáticas, sendo agora mais comumente usada no manejo cirúrgico de tumores malignos dos membros superiores. Apesar da complexidade e da agressividade da cirurgia, é um procedimento relativamente seguro com intuito de aliviar a dor e melhorar a qualidade de vida de pacientes selecionados portadores de tumores irressecáveis, metastáticos ou não, das extremidades superiores dos membros. ${ }^{4,6,11,13}$

\section{CONCLUSÃO}

A Cirurgia Oncológica deve enquadrar um tratamento radical da doença de base. A amputação é um procedimento de considerável impacto funcional, psicológico e social para o paciente, ${ }^{1}$ devendo ser indicada apenas em situações muito bem selecionadas. No caso relatado, optamos pela Desarticulação Interescapulotorácica devido à presença de um tumor localmente avançado, a não funcionalidade do membro, a possibilidade de melhor higienização local e a ausência de metástases em outros sítios. Assim, a radicalidade deste procedimento é justificada pela possibilidade de se tratar de uma terapêutica de cura, além do ganho na qualidade de vida da paciente, uma vez que ocorreu expressiva e sustentada resolução do quadro álgico. 


\section{REFERÊNCIAS:}

(1) Amputação de membros por carcinoma escamocelular da pele Fatores envolvidos nesta evolução desfavorável. Wainstein AJA, Oliveira TA, Guelfi DCF, Gontijo BR, Castro EV, Carvalho RA, Paz NM, Lacerda LT. Rev Col Bras Cir [periódico na Internet] 2012; 39(3)

(2) Cutaneous squamous cell carcinoma. Murad Alam, Désirée Ratner. $N$ Engl J Med, Vol. 344, No. 13 March 29, 2001.

(3) Delayed metastases in skin cancer of the head and neck: the case of the "known primary". Talmi YP, Horowitz Z, Wolf M, Kronenberg J. Ann Plast Surg. 1999 Mar;42(3):28992.

(4) Forequarter amputation for malignant tumours of the upper extremity: Case report, techniques and indications. $\mathrm{V}$ Dimas, J Kargel, J Bauer, P Chang. Can J Plast Surg 2007;15(2):83-85.

(5) Incidence of basal cell and squamous cell carcinomas in a population younger than 40 years. Christenson et al. JAMA, August 10, 2005 - vol 294, $n^{\circ} 6$.

(6) Interscapulothoracic Amputation of the Shoulder. Norman B. Carson. Ann Surg. 1913 June; 57(6): 796-804.

(7) Managing patients with cutaneous squamous cell carcinoma metastatic to the axilla or groin lymph nodes. Amy Goh, Julie Howle, Michael Hughes, Michael J. Veness. Australasian Journal of Dermatology (2010) 51, 113-117.

(8) Metastatic cutaneous squamous cell carcinoma: an update. Weinberg et al. Dermatol Surg 2007; 33: 885-899.
(9) Microstaging of squamous cell carcinomas. Breuninger H, Black B, Rassner G. Am. J. Clin. Pathol. 1990; 94: 624-7.

(10) Ministério da Saúde / Instituto Nacional do Câncer (INCA). www.inca.gov.br

(11) Proximal major limb amputations - a retrospective analysis of 45 oncological cases. Adrien Daigeler, Marcus Lehnhardt, Ammar Khadra, Joerg Hauser, Lars Steinstraesser, Stefan Langer, Ole Goertz and HansUlrich Steinau. World Journal of Surgical Oncology 2009, 7:15.

(12) Surgery and adjuvant radiotherapy in patients with cutaneous head and neck squamous cell carcinoma metastatic to lymph nodes: combined treatment should be considered best practice. Veness MJ, Morgan GJ, Palme CE, Gebski V. Laryngoscope 2005;115:870-5.

(13) Tratamento cirúrgico de tumores malignos envolvendo ombro e membro superior: estudo de 10 casos Leonardo José Vieira; João Paulo Vieira; Alexandre Ferreira Oliveira; Rosyane Rena de Freitas; Felipe Torres Rabêlo; Rafael Rabello Lista Mira e Jean Khoury José. Revista Brasileira de Cancerologia 2004; 50(2): 127-132

(14) Treatment of unresectable and metastatic cutaneous squamous cell carcinoma. Cranmer. Engelhardt. Morgan. The Oncologist 2010; 15: $1320-1328$.

World Health Organization Classification of Tumours. Pathology and Genetics os Skin Tumours. Philip E. LeBoit, Günter Burg, David Weedon, Alain Sarasin. Lyon. 2006 